\title{
The high altitude cultures of India: perception of new paradigms
}

\begin{abstract}
High altitude is often referred to places above sea level, which are not uncongenial for human settlement having certain problems and other basic facilities titled. People living in these threatening areas are struggling to survive and their cultures as their place are not at all sociable. The advent of this concept from a Curator's mind for strengthening the Cultures to the public domain has been a long route. In the proposed presentation a new paradigm is presented, India being one of the countries with diversified Ethnic representations needs to be strengthened with an Integrated Ethnographic studies and Anthropological approaches. The idea is to explore the possible traits and elements of Social Integration from the isolated areas of India to maintain peace, harmony and healthy socio-cultural and economic growth. The global forces that existed with easy access to the massive portals of information technology no more remain isolated from the purview of Museums. This new trend of technological advancement may rightly be utilized towards the social integration of high altitude people, examining how appropriate design can help to render services for development of these people and will explore a new paradigm. The new paradigm through in exquisite Museum case studies held at different target groups of Leh-ladakh and Kargil districts of J\&K. Statistical information pertaining to the range of data collected from the Changpa Nomads of Tso-kar region and Brokpa tribe of Tiger hills, Kargil. A sensible amount of arrangement made in contextualizing the need of information to arouse a sense of respect to the High Altitude Cultures was one of the prime focus, along with the participatory approaches applied in field to affirm and preserve the elements of cultural identity. The findings would open a new paradigm for the researchers on the passive way of Museum research.
\end{abstract}

Volume 4 Issue 3 - 2019

Banita Behera

Assistant Keeper, Anthropological Survey of India, Port Blair

Correspondence: Banita Behera,Assistant Keeper, Anthropological Survey of India, Andaman and Nicobar Islands, Port Blair, Email banita.musres@gmail.com

Received: April 05, 2019 | Published: June 20, 2019

Keywords: high altitude, culture, cultural adaptation, tribe, new paradigm

\section{Introduction}

Since the time immemorial man has been depending on its environment for his livelihood from minimum to the maximum level. ${ }^{1}$ From prehistoric time onwards Anthropologist has gathered innumerable evidences regarding the close and intricate relationship between man and environment. In the studies of ecological anthropology especially human ecology though we have the scope and capability to specialize on the studies of man-environment relationships, because of certain inhospitable circumstances no much work have been done so far. Therefore, the continuity as well as extension of such studies in inhospitable, adverse environmental situations has been minimized in India. This has resulted severe flaws in anthropological understanding of man environment relationship as well as understanding of High-altitude Cultures. ${ }^{2}$ Mostly high altitude areas are confined to the Himalayan belt of Northern India. Except few regions of Nepal and Uttarakhand in most of the areas because of inaccessibility, no anthropological study was possible in the past. Because of this, we lack substantial data in the fields of border line migration, socio-cultural interaction and the continuity of social identity of certain high altitude communities mostly in the field of Anthropology (Figure 1). ${ }^{3}$

Such an ecological enquiry will have manifold contributions not only in the field of social sciences but also for the central as well as State Government's basic requirements. Lack of oxygen, basic amenities for minimum living and absence of motorable road may be the causes for keeping such areas relatively isolated from the main land, but from administrative point of view it was a basic need for any Government to maintain contact with such areas, for the sake of the development of the people. ${ }^{4}$ May be because of such man made factors of isolation and complete lack of any anthropological exploration in such areas, initiated interest to take up such a Himalayan enquiry for research leading to this paper.

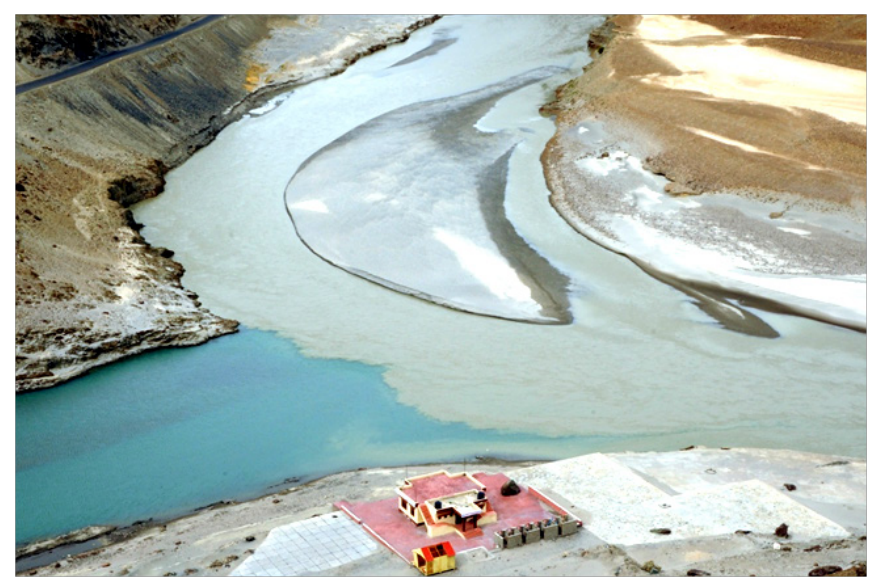

Figure I Meeting point of Zanskar and Indus river, Ladakh, Jammu \& Kashmir.

The selection of certain communities in between $8,000 \mathrm{ft}$ to $15,000 \mathrm{ft}$ altitude in order to understand as well as explain the degree of high 
altitude adaptability to different altitude points. Besides adaptation to local environmental situations, there was also a need to explore historically people's migration from far off places and to develop adaptation to such high altitude regions. From the contemporary study of culture through we understand the livelihood systems of the people and their associated socio-cultural institutions, without enquiring the historical past no fact can explain their background so well. While enquiring about the past historical tradition, the reasons and purposes of migration will be also made very clear for the explanation of the current situations and leads to a new paradigm. Besides the diachronic and synchronic enquiries, the inter- ethnic interaction in the context of nomadism and semi nomadism for the quest of food, their ways of trans-humance help in a grand way to explain their seasonal movement, the interaction among Chinese, Tibetan and Indian Nomads and the overall exploration of sedentarisation process through various ritual celebrations (Table 1).

Table I Showing selected communities for the study

\begin{tabular}{|c|c|c|c|c|c|}
\hline SI. no & Zone & Villages & Communities & $\begin{array}{l}\text { Maximum } \\
\text { elevation }\end{array}$ & Reference \\
\hline I & North/east Ladakh & Kharnak,Rupsho, Korzok, Hanle & $\begin{array}{l}\text { Changpa,Brokpa, } \\
\text { Sherpa and Moriries }\end{array}$ & $15,075 \mathrm{ft}$ & Non-motorable areas \\
\hline 2 & South ladakh & $\begin{array}{l}\text { Darsik, Garkhun, Gurgurdo,Daraj, } \\
\text { Kharnak ,Toso Moriri, }\end{array}$ & Dongpa,Balti, Rupshu & $17,582 \mathrm{ft}$ & Motorable area \\
\hline 3 & West Ladakh & $\begin{array}{l}\text { Zanskar,Rangdum(isolate village), } \\
\text { Kansha, Zangha, Samad }\end{array}$ & Zanskari & $18320 \mathrm{ft}$ & Motorable area \\
\hline 4 & Arunachal Pradesh & Kanggardo Rize & Mongpas & $7,090 \mathrm{ft}$ & Non-motorable areas \\
\hline 5 & Sikkim & $\begin{array}{l}\text { Kanchenjunga, North Sikkim, the } \\
\text { India-Nepal border }\end{array}$ & Tibetan Bhutias, Lepcha & $8,586 \mathrm{~m}(28,169 \mathrm{ft})$ & Non-motorable areas \\
\hline
\end{tabular}

Such interesting issues automatically help to study the sustainable livelihood pattern in a very difficult geographical terrain. From the pilot survey it has been very interestingly gathered that as per the people's version in the north-western part of Himalaya three communities said to be Chinese nomads, Tibetan nomads, and descendants of Alexander, the Great, usually inhabit a contiguous area maintaining some sort of socio-cultural interaction as well as integration. While enquiring about three different types of communities depending upon the same surrounding environment, several interesting dimensions crop up for this anthropological study. ${ }^{5}$ The migration history and the livelihood system have already been maintained for study the other interesting dimensions are in such Ladakh regions, where some tribes are maintaining a nomadic life where as others are settled agriculturists along with a very common profession of Pashmina processing as well as marketing units. The other interesting dimension which leads to a new paradigm is that within the area of Human ecology, it will be very important to explain that how Tibetan Indian adheres a nomadic way of life and the Chinese Indians maintain a settled agriculturist economy (Figure 2).

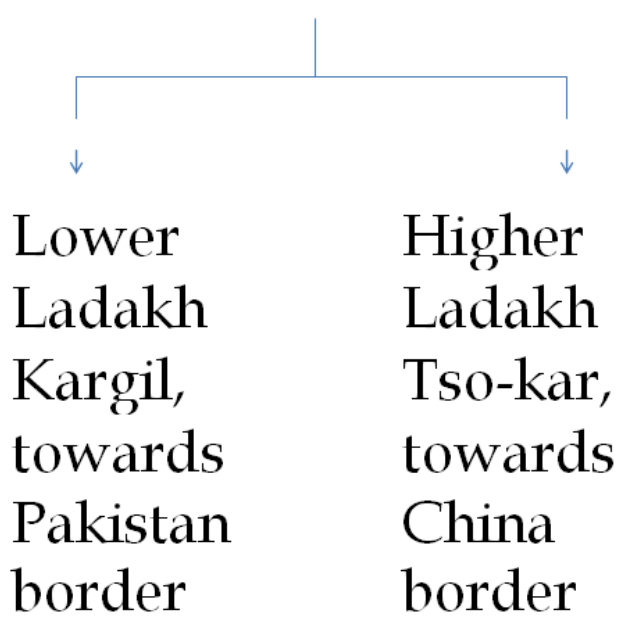

Figure 2 Certain communities in between $8,000 \mathrm{ft}$ to $15,000 \mathrm{ft}$ altitude.

\section{High altitude and culture}

According to beliefs, the Ladakh region was once home to a major population of the Darads. This belief has been found somewhat true after the archaeological findings in the region. The presentday population of the Mongoloid descendants can be attributed to the migration of their ancestors in the past. Human settlements in the Himalayas have also been highly influenced by topography and economic patterns. But climatic conditions remain the most important factor since extreme climate in the Himalayan region has always imposed restrictions on the living conditions and also restricted communication and movement (Figure 3). ${ }^{6}$

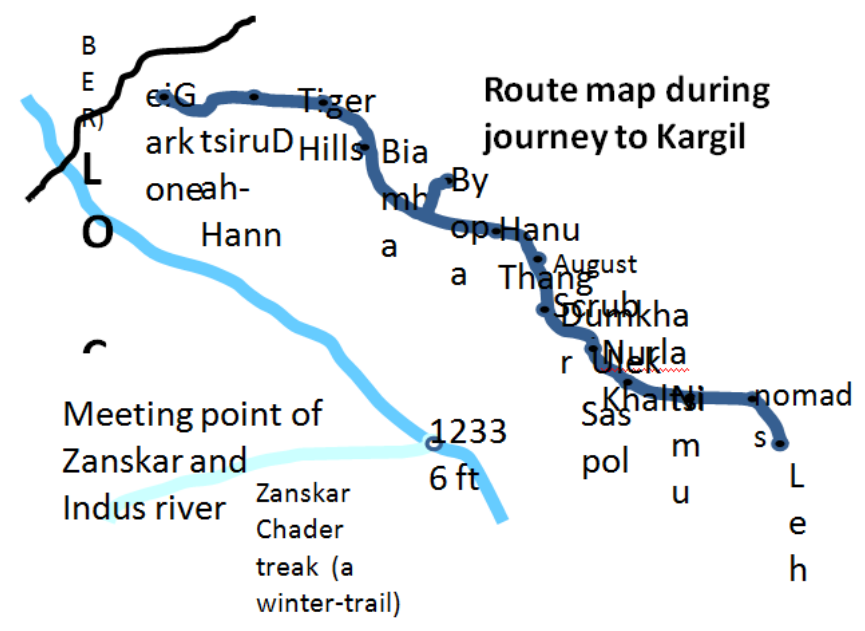

Figure 3 Route mapping during Journey to Kargil.

\section{About the communities}

1. Brokpa (people's designation as 'Arayan')- In Dah-Hanu and Garkone villages.(8,000ft to $10,000 \mathrm{ft}$ altitude)

2. Changpa(Tibetan-Indian nomads)- In Changthang area(above $15,000 \mathrm{ft})$ 
3. Drokpa(Chinese- Indian nomads)- In Namzong rakh area (above $15,000 \mathrm{ft})$

The word Brok means high pasture land and Brokpa means Highlander people. The community calls itself Minaro (meaning Aryan), but are popularly known as Brokpa. They are part of the Dards some of whom are found in isolated pockets of India are popularly known as Brokpa. The Changpa are a semi-nomadic Tibetan people found mainly in the Changtang in Ladakh region. These Nomads are remarkable people who live in extreme conditions in remote cold barren mountains. These are high altitude pastoralists, raising mainly yaks and goats. They live mainly from the sale of the goat wool that is used to make the famous Pashmina wool (Pashmina goat is prized for its wool and the extreme cold air on high altitude encourages good quality wool). The average altitude of 4000 meters, too hostile to culture, but ideal for grazing, brings the people of the region to follow their herds during the summer milder season. During the winter, the harsh climate does not allow them to live in camps; they join then their permanent housing in urban areas.

The Drokpa (Chinese Indians) along with the Changpa (Tibetan Indians) in certain seasons make seasonal movement to lake

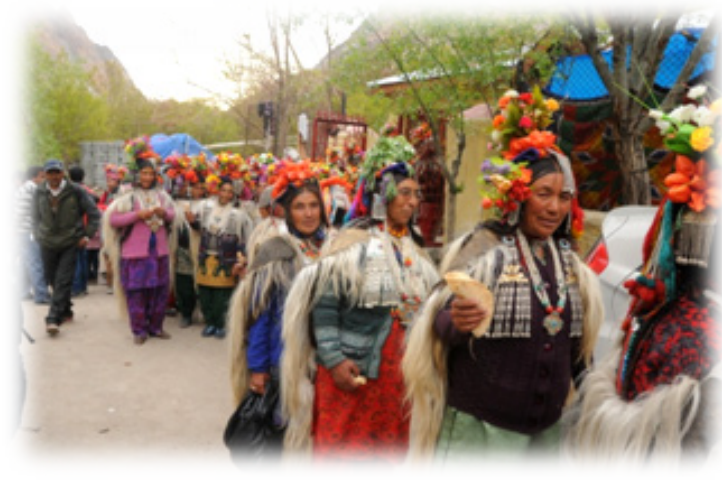

Figure 4 Brokpa (people’s designation as ‘Arayan'), and Drokpa(Chinese- Indian nomads)- In Namzong rakh area (above I5,000ft).

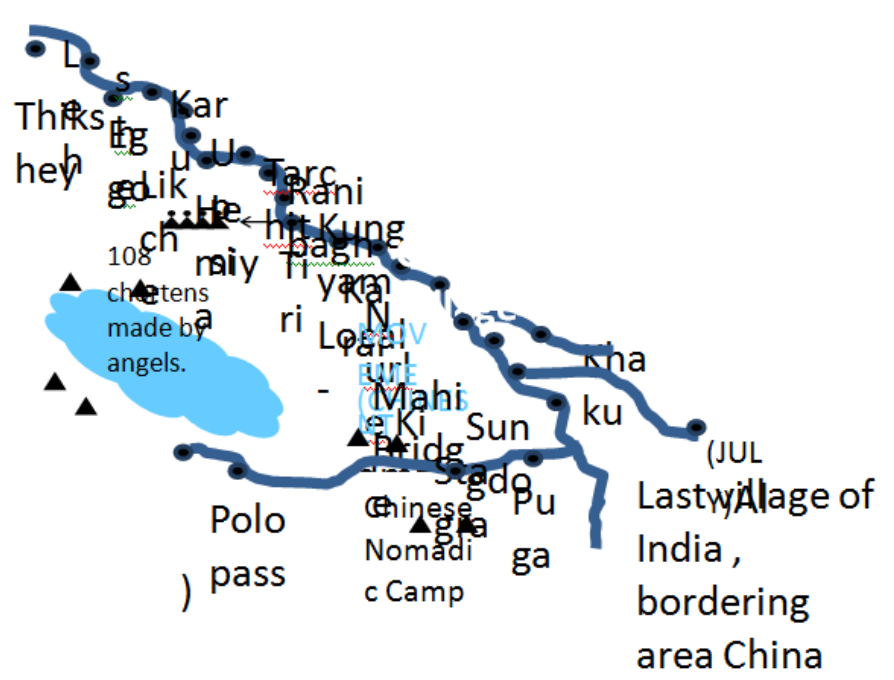

Figure $5 \mathrm{~A}$ route towards Higher Ladakh, Chagthang area.

\section{The facts leading to new paradigm}

Firstly, this place is the borderline of Pakistan and India which has been popularized after the Kargil war and here inhabit a particular tribal side grazing areas. Whereas the Brokpa otherwise called as the decedents of Alexander don't opt for cattle grazing, the other two communities, Chinese nomads (Drokpa), Tibetan nomad (Changpa) besides nomadism continue a pastoral way of life which supports both nomadism/ seasonal migration and the business of Pashmina/ wool. From human ecological point of view Drokpa and Changpa belong to similar socio-cultural traditions, where as the Brokpa, the decedents of Alexander are said to be settled with a different sociocultural setup. Therefore, in this Ladakh region such 3 communities while continuing two different socio-cultural traditions maintain 3 different types of ecological adaptation. Moreover, it was also very interesting to observe that while in trans-humance movement the Changpas and Drokpas meet each other only during ritual celebration/ festivals (Figure $4 \& 5$ ). It is needless to mention that such high altitude environment creates specific deficiency of oxygen beyond $10,000 \mathrm{ft}$ altitude. Therefore, along with the socio-cultural coping mechanism with the environment, the biological maintenance of life also renders some pinpointed anthropological interest. Taking various historical cultural roots and factors observed and explained for the understanding and explanation of this mysterious high altitude cultural coping mechanism in a grand way.

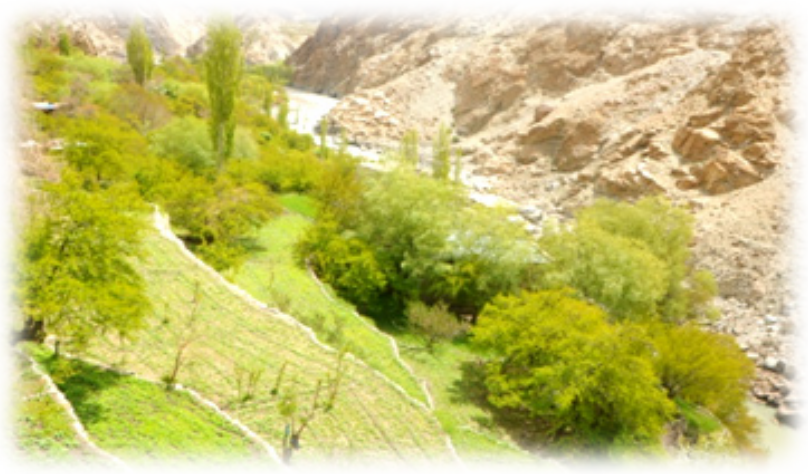

community designated as Brokpa as per the local term who identify themselves as 'Aryans' tracing their origin from the descendants of Alexander, the Great from Macedonia to Gilgit following which the so called Brokpas originated in the locality especially in the villages of Dah-Hanu and Garkone. Narrating the song, some of their words are still same and dances too as like the Arayans, They worship the same God and follows same music which leads their belief strong that they are the ancestor of Alexander the great. The collected emic points from the Brokpa was the first fact that brought interest in the study to cross verify and conduct a social enquiry behind it. 'We are Aryans, the decedents of Alexander the Great, our ancestors was at Gilgit', instead of accepting these data a socio-cultural enquiry of all was essential to bring brownie points to highlight the observations. ${ }^{7}$

("All primitive cultures have their own unique and particular histories..."-Franz Boas) It is a belief of the Brokpa that their ancestors were came with Alexander and stayed at Gilgit (Pakistan), bordering to Kargil. The need of historical exploration, their migration from far off places and the contemporary study of certain tangible and intangible traits through we able to understood their associated historical past. Without enquiring the historical past no fact can explain their background so well. While enquiring about the past historical tradition, and cultural roots the reasons and purposes of migration were also made very clear for the explanation of their current situations (Figure 
6). Secondly, in this particular high altitude ecosystem two other communities who were originally pastoral nomads live in the adjacent areas like Namzong Rakh, Rupshu (Samad basin) who are known as Chinese nomads and Tibetan nomads respectively. Whereas the interaction, distribution and reassemble of Changpa nomads during their seasonal movement for the quest for food, was another grand way to explain the overall exploration of sedentarization process with inter-ethnic interaction (Figure 7).

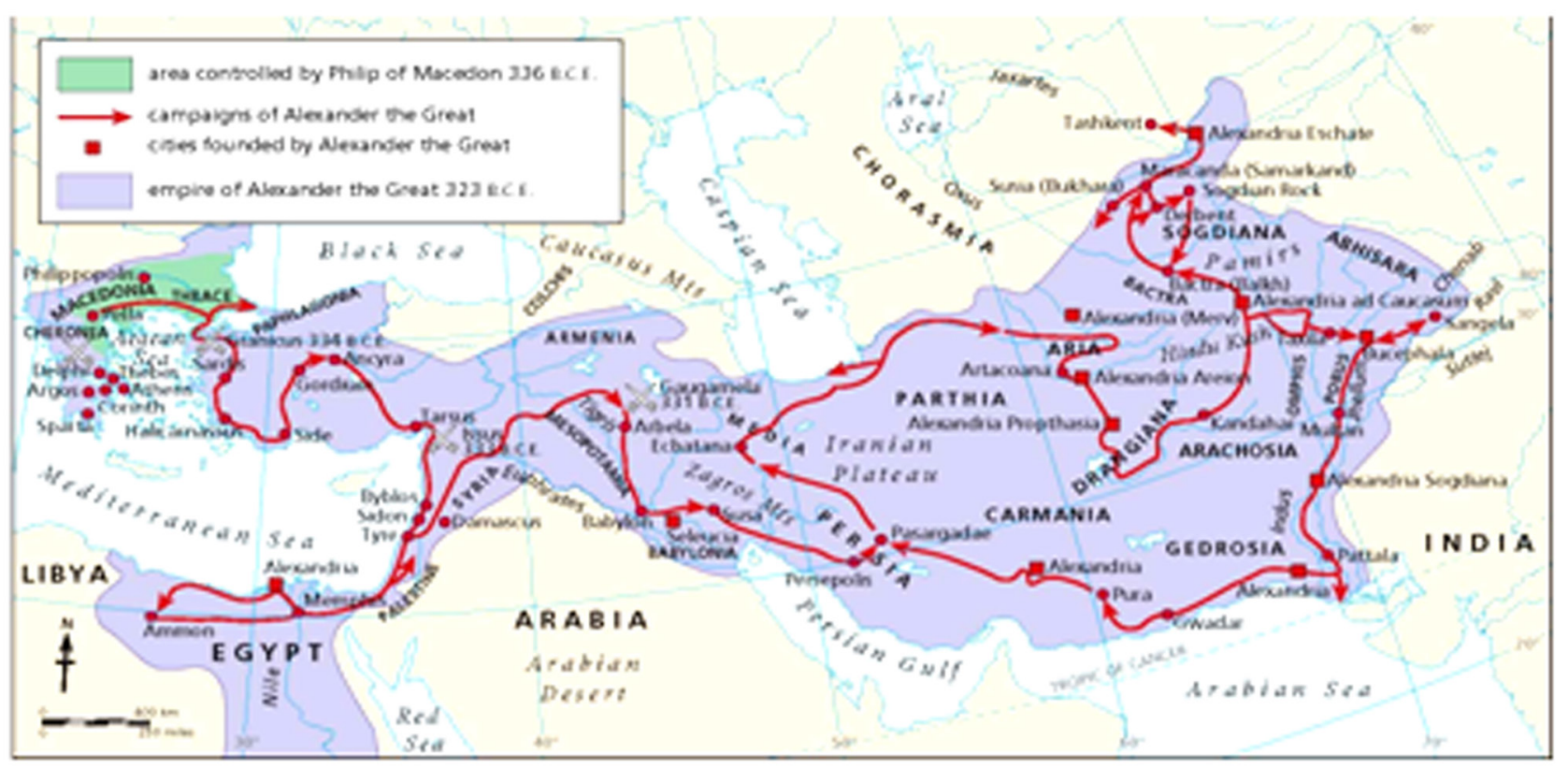

Figure 6 Map showing route of Alexander the Great to India.

Changpas during movement

$\begin{array}{lll}\text { Changpa } & \begin{array}{l}\text { Drokpa } \\ \text { (Chinese } \\ \text { nomads) }\end{array} & \begin{array}{l}\text { Korba } \\ \text { (who heard } \\ \text { the } \\ \end{array} \\ & \begin{array}{l}\text { Gonpa's } \\ \text { livestock ) }\end{array}\end{array}$

Figure 7 Categorization of Changpa during Seasonal movement.

The best of my knowledge the present discourse try to understand the biosocial adaptability and cultural specificity with special reference to trace the traditionality of the three adjacent communities in Ladakh; the interrelated study is being analysed for comparative statement using social anthropological methodology keeping in mind the High altitude backdrop of the ecology considered (Figure 8 \& 9). At the outset the mythological and other documented history of the Brokpa, Changpa and Drokpa that gathered both from the primary and secondary sources had traced some socio-cultural linkages which may sow the seed of cultural exchange bonding with two countries. Secondly, the detailed ethnographic account of the three tribes which has collected and compared with specific attention it may carefully analyzed the social structure/organization/system (family, marriage and kinship) of the three communities for showing their relatedness and adaptation to the high altitude environment. On the whole, the socio-cultural adaptability of the Brokpa, Changpa and Drokpa who are from outside cultural tradition of India were assessed on the basis of values, customs, rituals and the overall religious practices through this study (Figure 10).

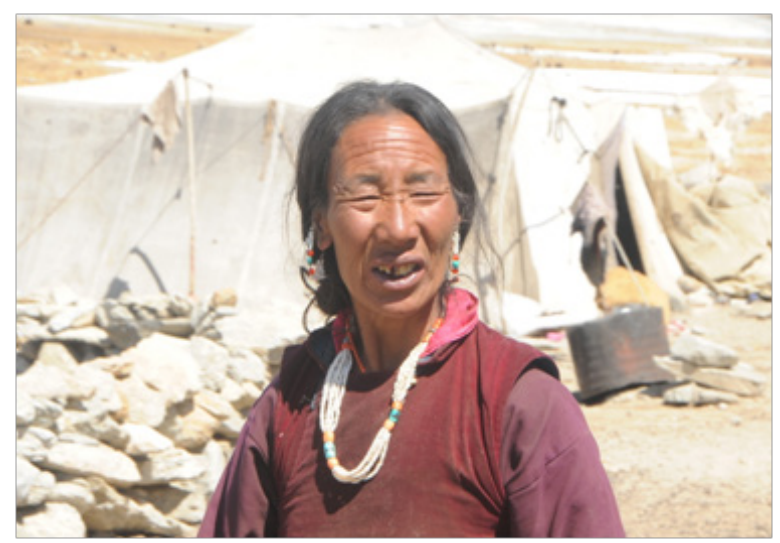

Figure 8 A Changpa lady.

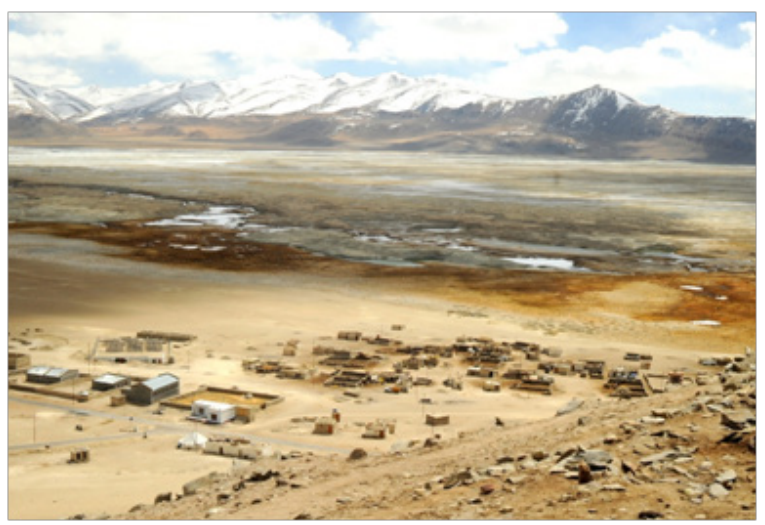

Figure 9 A bird's eye view of Rupshu. 


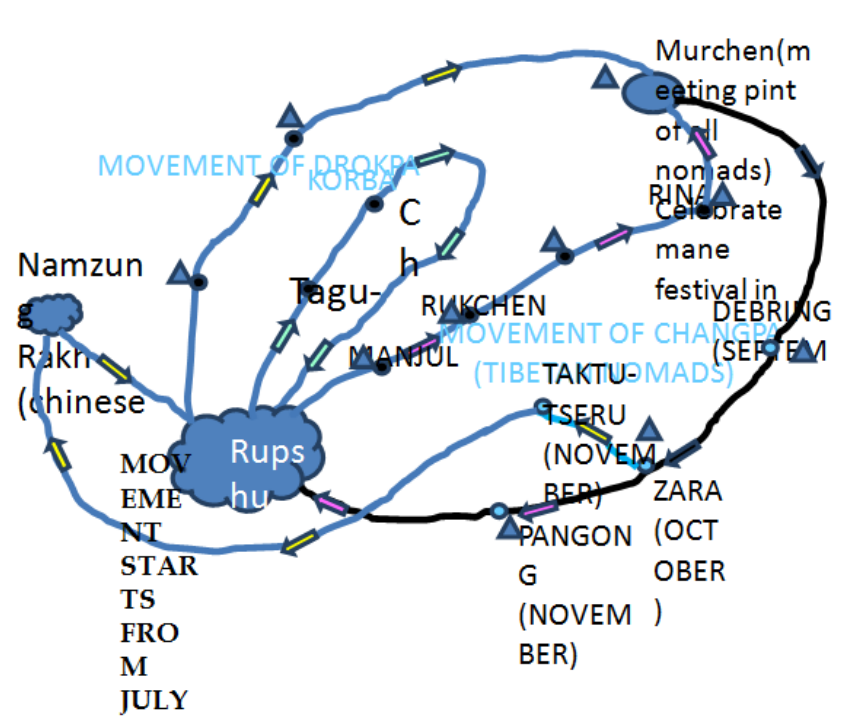

Figure 10 Movement of Drokpa.

\section{Discussion}

For the present discourse on certain communities in between $8,000 \mathrm{ft}$ to $15,000 \mathrm{ft}$ altitude in order to understand as well as explain the degree of high altitude adaptability to different points. Besides adaptation to local environmental situations, there was also a need to explore people's migrational history from far off places and to develop adaptation to such high altitude regions. From the contemporary study of culture though we understand the livelihood systems of the people and their associated socio-cultural institutions, without enquiring the past no fact can explain their background so well. The present work was basically an empirical one because of which emphasis have been given on primary source data collection through first hand contact. This approach is basically synchronic with some sort of diachronic background for getting into the socio-cultural and demographic details of the community. ${ }^{8-11}$ The challenges that present Ladakh region faces now is how to cope with the present transaction from remote to an isolated region to developed region without losing its rich traditional culture. The change in the pattern of local resource usage has already started to change the livelihood pattern in the region. The shift has also been very visible in the lifestyle of nomadic people living in the remote regions of Ladakh; due to lack of pasture development the rearing of livestock animals have decreased incredibly.

\section{Acknowledgments}

None.

\section{Conflicts of interest}

Author declares that there is no conflict of interest.

\section{References}

1. Saravanan R. Traditional Knowledge, Innovation System and Democracy of Sustainable Agriculture: A Case Study of Adi Tribes of Eastern Himalayas of North East India. ISDA. 2010.

2. Ahmed Monisha. Living Fabrics: Weaving among the nomads of Ladakh Himalayas. USA: Weather hill Inc; 2002.

3. Bhasin Veena. Himalayan Ecology. Transhumance and Social Organisation. Delhi: Kamla-Raj Enterprises; 1988.

4. Blaikie C. Why do the Nomads Settle? Livelihood, Sustainability and Rural-Urban migration among the Kharnak Community of the Chang-pa of Ladakh. M.Sc. Dissertation, University of London; 2001.

5. Hagalia Wenche. Changing Rangelands use by the nomads of Samad in the highlands of Eastern Ladakh, India. Master thesis, Agriculture University of Norway; 2004.

6. Srinivasan S. Mapping the Tso Kar basin in Ladakh: Gathering Spatial Information from a nomadic community. The Journal of Community Informatics. 2012;8(2).

7. Dollfus P. Mountain deities among the nomadic communities of Kharnak (Eastern Ladakh). In: M Van Beek, K Brix Bertelsen, P Pedersen, editors. Ladakh: Culture, History and Development between Himalaya and Karakoram. Aarhus, Denmark: Aarhus University Press; 1999.

8. Chaudhuri A. The Changpas of Rupshu-Kharnak: An inquiry into the survival strategies of an amazing People. Unpublished report. New Delhi: Action-Aid; 1999.

9. Ahmed Monisha. The salt trade: Rupshu's annual trek to Tso-Kar. Recent Research in Ladakh. 1999;8:32-48.

10. Bhasin Veena. Transhumants of Himalayas: Changpas of Ladakh, Gaddis of Himachal Pradesh and Bhutias of Sikkim. Delhi: Kamla Raj Enterprises; 1996.

11. Bhasin V. Life on an Edge among the Changpas of Changthang, Ladakh. J Biodiversity. 2012;3(2). 